\title{
Overexpression of papillomavirus binding factor in Ewing's sarcoma family of tumors conferring poor prognosis
}

\author{
HIROKI YABE ${ }^{1}$, TOMOHIDE TSUKAHARA ${ }^{3}$, SATOSHI KAWAGUCHI ${ }^{3}$, TAKURO WADA ${ }^{3}$, \\ NORIYUKI SATO ${ }^{4}$, HIDEO MORIOKA ${ }^{2}$ and HIROO YABE ${ }^{2}$ \\ ${ }^{1}$ Department of Orthopaedic Surgery, National Hospital Organization Tokyo Medical Center; ${ }^{2}$ Department of \\ Orthopaedic Surgery, School of Medicine, Keio University, Tokyo; Departments of ${ }^{3}$ Orthopaedic \\ Surgery, and ${ }^{4}$ Pathology, Sapporo Medical University School of Medicine, Sapporo, Japan
}

Received August 1, 2007; Accepted September 28, 2007

\begin{abstract}
Ewing's sarcoma family of tumors (ESFT) is comprised of highly malignant bone and soft tissue tumors in children and young adults. Despite intensive treatments for patients with ESFT, disease which presents with metastatic spread or relapses after primary treatment remains incurable in the majority of cases, indicating the importance of efforts to develop new treatment modalities, including immunotherapy. The present study was designed to examine the expression profile of papillomavirus binding factor (PBF), which we previously defined as an osteosarcoma-associated antigen, and its prognostic significance for patients with ESFT. Biopsy specimens from 20 ESFT were stained with an antiPBF antibody. Survival was estimated using Kaplan-Meier plots and the prognostic significance of several variables, including the expression status of PBF, on disease-free and overall survival was determined by univariate analysis using the log-rank test. Of 20 specimens, $18(90 \%)$ reacted positively to the anti-PBF antibody. Fifteen specimens (75\%) were graded as PBF overexpression. Of the 11 variables analyzed, stage III disease, inadequate surgical margins and PBF overexpression were significantly associated with decreased disease-free and overall survival. None of the other variables, including age, gender, origin of tumor, tumor site or levels of LDH, ALP, CRP and ESR, showed any significant association. These findings indicate that the overexpression of PBF is a factor indicative of poor prognosis in ESFT. PBF may also serve as a putative target antigen in immunotherapy for patients with ESFT that have a poor prognosis and PBF overexpression.
\end{abstract}

Correspondence to: Dr Satoshi Kawaguchi, Department of Orthopaedic Surgery, Sapporo Medical University School of Medicine, South 1, West 16, Chuo-ku, Sapporo 060-8543, Japan

E-mail: kawaguch@sapmed.ac.jp

Key words: immunohistochemistry, Ewing's sarcoma family of tumor, papillomavirus binding factor, tumor-associated antigen, prognostic factor

\section{Introduction}

Ewing's sarcoma family of tumors (ESFT) is comprised of highly malignant bone and soft tissue tumors in children and young adults (1). Although systemic adjuvant chemotherapy has significantly improved the prognosis for patients with ESFT, disease which presents metastatic spread or relapses after primary treatment remains incurable in the majority of cases $(2,3)$.

After a nearly 30-year interval from the initial immunotherapeutic trials for osteosarcoma $(4,5)$, immunotherapy has recently re-emerged as a targeted therapy for bone and soft tissue sarcomas, including ESFT $(6,7)$. In a clinical trial with ESFT patients, peptides derived from the junction regions of EWS-FLI1 fusion genes were used as ESFT-specific vaccines (6). However, clinical response was seen in only 1 of the 12 patients enrolled, suggesting the importance of finding further efficacious antigens and of developing antigenic peptide vaccines (8).

Recently, papillomavirus binding factor (PBF) was identified as an autologous cytotoxic T-lymphocyte-defined osteosarcoma antigen (9). It was originally defined as a transcriptional regulator of genomic DNA of human papillomavirus type 8 (10). The antigenic and oncologic roles of PBF in ESFT remain uncertain. In this study, with the aim of gaining basic information on these aspects of PBF, we examined its expression in 20 cases of ESFT and analyzed its prognostic significance.

\section{Materials and methods}

This study was approved according to institutional guidelines for the use of human subjects in research. Patient specimens were analyzed after informed written consent was obtained from the patients or their families.

Patients and samples. Between 1979 and 2005, 20 consecutive patients with ESFT were treated at Keio University hospital. The clinical picture is summarized in Table I. There were 12 male and 8 female patients, with an average age at diagnosis of 23.9 years (range, 1-63 years). Twelve tumors arose from bone and the remaining 8 from soft tissue. Eight tumors were located in the trunk and 13 in the extremities. Fusion genes, including 
Table I. Clinical characteristics and expression status of PBF in patients with ESFT.

\begin{tabular}{|c|c|c|c|c|c|c|c|c|c|c|}
\hline Patient & $\begin{array}{c}\text { Age } \\
\text { (years) }\end{array}$ & Gender & Location & Stage $^{\mathrm{a}}$ & Fusion gene & Treatment & $\begin{array}{l}\mathrm{PBF} \\
\text { status }\end{array}$ & $\begin{array}{c}\text { Event-free } \\
\text { survival } \\
(\mathrm{mos})\end{array}$ & $\begin{array}{c}\text { Overall } \\
\text { survival } \\
\text { (mos) }\end{array}$ & Prognosis \\
\hline \multicolumn{11}{|l|}{$\begin{array}{l}\text { Bone } \\
\text { tumor }\end{array}$} \\
\hline 1 & 1 & M & Right tibia & IIB & ND & $\mathrm{Chx}(\mathrm{VAC})+\mathrm{Amp}+\mathrm{Rx}$ & ++ & 179 & 179 & $\mathrm{CDF}$ \\
\hline 2 & 36 & $\mathrm{~F}$ & Right femur & IIB & ND & $\mathrm{Chx}(\mathrm{A}-\mathrm{VAC})+\mathrm{Amp}+\mathrm{Rx}$ & - & 174 & 174 & $\mathrm{CDF}$ \\
\hline 3 & 16 & M & Right humerus & IIB & ND & Chx $(A-V A C)+W E+R x$ & + & 250 & 250 & $\mathrm{CDF}$ \\
\hline 4 & 13 & M & Left tibia & IIB & ND & Chx (CYVADIC) + WE + Rx & +++ & 166 & 166 & $\mathrm{CDF}$ \\
\hline 5 & 17 & M & Thoracic spine & IIB & EWS/ERG & Chx $(\mathrm{T} 11)+\mathrm{ME}+\mathrm{Rx}$ & +++ & 8 & 45 & DOD \\
\hline 6 & 16 & M & Sacrum & IIB & ND & Chx $(T 11)+W E+R x$ & ++ & 99 & 99 & $\mathrm{CDF}$ \\
\hline 7 & 16 & $\mathrm{~F}$ & Left tibia & IIIB & EWS/FLI-1 & Chx $(\mathrm{KS}-1)+\mathrm{WE}$ & +++ & 0 & 16 & DOD \\
\hline 8 & 22 & $\mathrm{~F}$ & Right fibula & IIB & EWS/FLI-1 & Chx $(\mathrm{KS}-1)+\mathrm{WE}$ & +++ & 108 & 108 & $\mathrm{CDF}$ \\
\hline 9 & 18 & M & Left 5 th rib & IIB & EWS/FLI-1 & Chx $(\mathrm{KS}-1)+\mathrm{WE}+\mathrm{Rx}$ & +++ & 105 & 105 & $\mathrm{CDF}$ \\
\hline 10 & 18 & M & Right fibula & IIB & EWS/FLI-1 & $\mathrm{Chx}(\mathrm{KS}-1)+\mathrm{WE}+\mathrm{Rx}$ & +++ & 7 & 21 & DOD \\
\hline 11 & 24 & M & Left tibia & IIB & EWS/FLI-1 & $\mathrm{Chx}(\mathrm{KS}-1)+\mathrm{WE}+\mathrm{Rx}$ & - & 15 & 15 & $\mathrm{CDF}$ \\
\hline 12 & 23 & M & Pelvis & IIIB & ND & Chx $(\mathrm{KS}-1)+\mathrm{Rx}$ & +++ & 0 & 17 & DOD \\
\hline \multicolumn{11}{|c|}{$\begin{array}{l}\text { Soft tissue } \\
\text { tumor }\end{array}$} \\
\hline 13 & 29 & M & Right thigh & IIIB & EWS/FLI-1 & Chx $(\mathrm{KS}-1)+\mathrm{ILE}+\mathrm{Rx}$ & +++ & 0 & 12 & DOD \\
\hline 14 & 63 & $\mathrm{~F}$ & Paraspine & IIB & ND & Chx $(\mathrm{KS}-1)+\mathrm{ILE}+\mathrm{Rx}$ & +++ & 0 & 71 & DOD \\
\hline 15 & 20 & $\mathrm{~F}$ & Right tibia & IIB & EWS/FLI-1 & $\mathrm{Chx}(\mathrm{KS}-1)+\mathrm{ME}+\mathrm{Rx}$ & +++ & 9 & 14 & DOD \\
\hline 16 & 56 & $\mathrm{~F}$ & Right forearm & IIIB & ND & Chx $($ CYVADIC + KS-1) + WE & +++ & 0 & 11 & DOD \\
\hline 17 & 7 & M & Paraspinal cord & IIB & Not detected & Chx $(\mathrm{KS}-1)+\mathrm{ME}$ & +++ & 14 & 16 & DOD \\
\hline 18 & 11 & $\mathrm{~F}$ & Paraspinal cord & IIB & EWS/FLI-1 & $\operatorname{Chx}(\mathrm{KS}-1)+\mathrm{ILE}+\mathrm{Rx}$ & +++ & 17 & 22 & DOD \\
\hline 19 & 35 & M & Left femur & IIB & ND & Chx $(\mathrm{KS}-1)+\mathrm{WE}$ & +++ & 126 & 126 & $\mathrm{CDF}$ \\
\hline 20 & 36 & $\mathrm{~F}$ & Right upper arm & IIB & Not detected & Chx $(\mathrm{KS}-1)+\mathrm{WE}$ & +++ & 101 & 101 & $\mathrm{CDF}$ \\
\hline
\end{tabular}

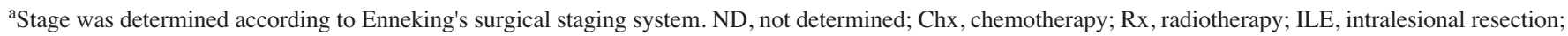
$\mathrm{ME}$, marginal excision; WE, wide excision; CDF, continuous disease free; DOD, death of the disease.

EWS/FLI-1, EWS/ERG, EWS/ETV1 and EWS/E1AF, were determined by RT-PCR (11) in 9 of the 11 cases for which frozen biopsy specimens were available. According to Enneking's surgical stage (12), 16 patients were in stage IIB and 4 in IIIB. Treatment consisted of chemotherapy and surgery for 6, chemotherapy, surgery, and radiotherapy for 13, and chemotherapy and radiotherapy for 1 . The chemotherapy protocols used were VAC (13), A-VAC (14), CYVADIC (15), T11 (16) and KS1, which is a modified protocol of New A3 (17). Radiotherapy (50-60 Gy) was instituted postoperatively. The average follow-up period after diagnosis was 78.4 months (range, 11-250 months).

Immunohistochemistry. Polyclonal antibody against PBF was generated previously (9). Formalin-fixed paraffin-embedded sections of biopsy specimens were boiled for $20 \mathrm{~min}$ in a microwave oven for antigen retrieval. Sections were blocked with $1 \%$ non-fat dry milk and stained with streptavidinbiotin-complex (Nichirei), followed by hematoxylin staining as previously described (9). The reactivity of the anti-PBF polyclonal antibody was determined by staining the nuclei. The expression status of PBF was estimated based on the number of tumor cells according to Ahmed et al (18) (Fig. 1): the presence of $\leq 5 \%$ of positively-stained tumor cells was represented by a minus (-), $6-25 \%$ by a plus $(+)$ and $26-60 \%$ by ++ . Overexpression, a number of positive tumor cells $>60 \%$, was represented by +++ .

Clinicopathological analysis. Survival was estimated using Kaplan-Meier plots. Univariate analysis with the log-rank test 

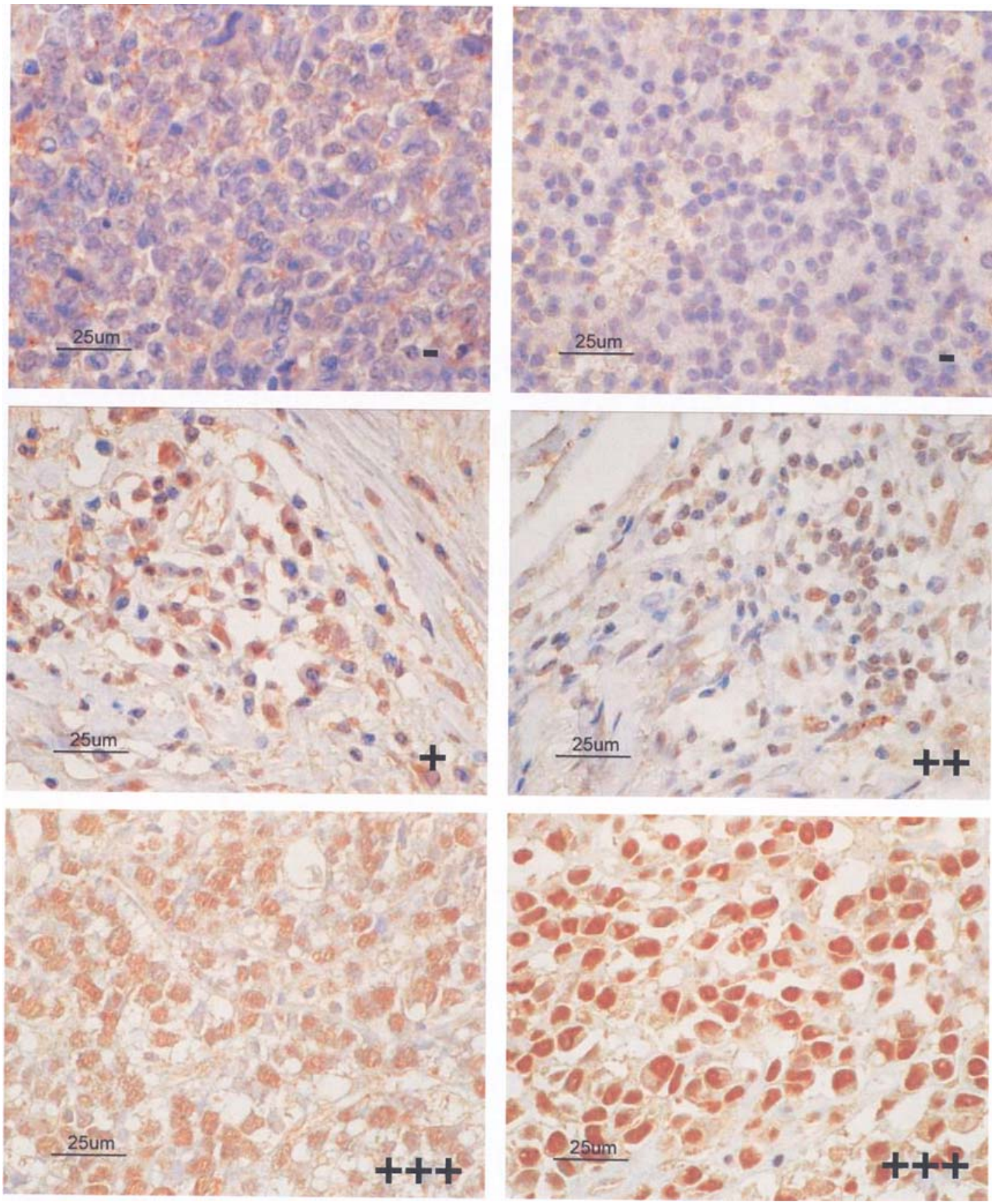

Figure 1. Immunohistochemical grading of PBF expression. Representative sections of ESFT specimens stained with anti-PBF antibody. Tumor cells showing positive reactivity in the nuclei were counted:,$- \leq 5 \%$ positive cells;,$+ 6-25 \%$ positive cells;,$++ 26-60 \%$ positive cells;,$+++>60 \%$ positive cells.

(19) was used to determine the prognostic significance of the following variables for disease-free and overall survival: age ( $\geq 30$ or $<30$ ), gender (female or male), tumor site (trunk or limb), origin of tumor (bone or soft tissue), stage (I, II or III), laboratory parameters (within or higher than normal range), surgical margin (adequate or inadequate) and PBF expression status $(-,+,++$ or +++$)$. Laboratory parameters included LDH, alkaline phosphatase (ALP), C-reactive protein (CRP) and the erythrocyte sedimentation rate (ESR) at $1 \mathrm{~h}$. Analysis of the surgical margins was performed in 16 stage IIB patients. Wide excision and amputation were regarded as adequate margins, whereas intralesional and marginal excision were regarded as inadequate. A probability of $<0.05$ was considered to be statistically significant.

\section{Results}

PBF expression in ESFT. To determine the expression profiles of PBF in ESFT, we stained 20 ESFT biopsy specimens with anti-PBF antibody. Of these, $18(90 \%)$ reacted positively to the anti-PBF antibody where the nuclei of tumor cells were stained (Fig. 1 and Table I). Two specimens were grade ++ and 1 was + . Fifteen specimens $(75 \%)$ were graded as +++ , indicating PBF overexpression.

Prognostic significance of PBF expression in ESFT. We then analyzed the prognostic significance of several variables, including the overexpression of PBF (grade +++ ). Overall survival rates of the 20 patients with ESFT were 53.1 and 


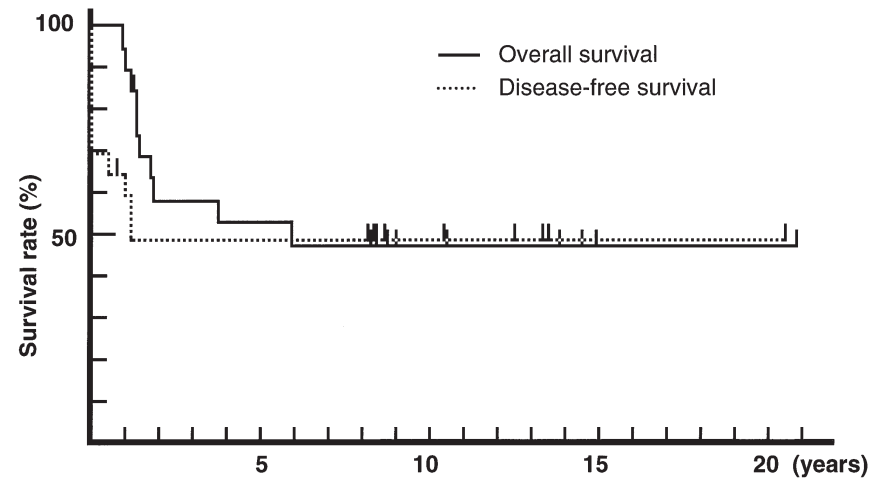

Figure 2. Overall survival of 20 patients with ESFT. Overall survival was estimated using Kaplan-Meier plots. The date of histological diagnosis was used as time 0 .

\section{A}

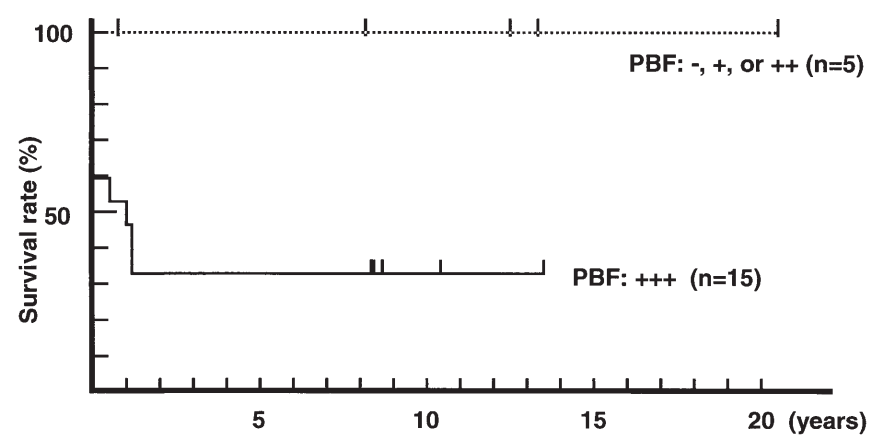

B

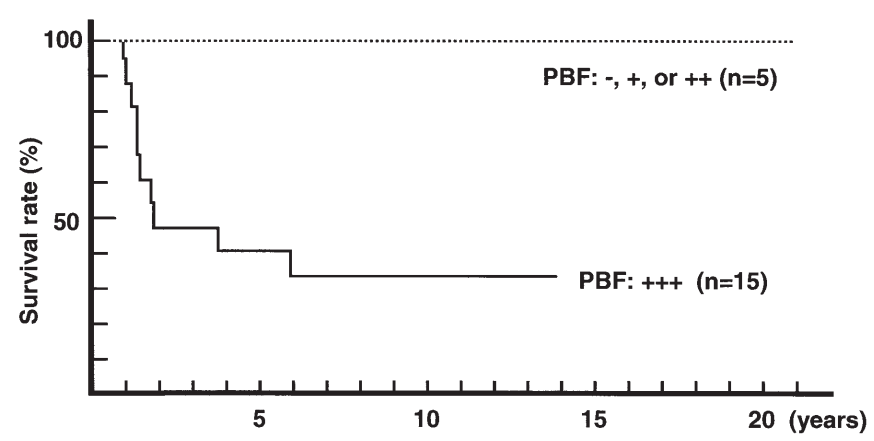

Figure 3. Survival curves of 20 patients with ESFT stratified by PBF expression status. (A) Disease-free survival curve. (B) Overall survival curve. Patients were divided according to PBF expression status into 2 groups (PBF expression of,,-+ and,$++ n=5$; PBF expression of,$+++ n=15$ ). Survival was estimated using Kaplan-Meier plots.

$47.8 \%$ at 5 and 10 years, respectively (Fig. 2). Of the 11 variables analyzed, stage III, an inadequate surgical margin and PBF overexpression of were significantly associated with decreased disease-free and overall survival (Fig. 3 and Table II). Of note, the overall survival of the 15 patients with PBF overexpression was $33.3 \%$ at 10 years, whereas 5 patients remained continuously disease free during the entire follow-up period. None of the other variables, including age,
Table II. Univariate analysis of potential unfavorable prognostic factors.

\begin{tabular}{lccr}
\hline & & \multicolumn{2}{c}{ P-value } \\
\cline { 3 - 4 } Factor & $\begin{array}{c}\text { No. of } \\
\text { patients }\end{array}$ & $\begin{array}{c}\text { Disease-free } \\
\text { survival }\end{array}$ & $\begin{array}{r}\text { Overall } \\
\text { survival }\end{array}$ \\
\hline Age ( $\geq 30$ years) & 5 & 0.71 & 0.54 \\
Male sex & 12 & 0.31 & 0.45 \\
Soft tissue tumor & 8 & 0.09 & 0.06 \\
Trunk tumor & 7 & 0.24 & 0.47 \\
Stage III & 4 & 0.006 & $\mathrm{P}<0.001$ \\
High ALP & 7 & 0.61 & 0.56 \\
High LDH & 8 & 0.34 & 0.51 \\
High CRP & 8 & 0.27 & 0.35 \\
High ESR & 8 & 0.30 & 0.46 \\
Inadequate & 6 & P $<0.001$ & $\mathrm{P}<0.001$ \\
surgical margin & & & 0.04 \\
PBF +++ & 15 & 0.04 & \\
\hline a'Marginal excision and intralesional excision & were regarded as inadequate \\
surgical margin and 16 stage IIB patients having undergone surgical treatment \\
were analyzed.
\end{tabular}

gender, origin of tumor, tumor site and levels of LDH, ALP, CRP and ESR, showed a significant association to disease-free or overall survival.

\section{Discussion}

By staining 20 biopsy specimens of ESFT treated at a single institute with an antibody against PBF we found i) that PBF was expressed in 18 ESFT specimens (90\%), including 15 specimens $(75 \%)$ with grade +++ overexpression, and ii) that PBF overexpression was significantly associated with the decreased disease-free and overall survival of patients. These findings indicate that the overexpression of $\mathrm{PBF}$ is a factor of poor prognosis for ESFT. PBF, which was originally defined as an osteosarcoma-associated antigen (9), may also serve as a putative target antigen in immunotherapy for patients with ESFT and PBF overexpression, which confers a poor prognosis.

Compared to malignant melanoma and epithelial cancers, there is a marked delay in the identification of tumorassociated antigens in bone and soft tissue sarcomas $(7,8)$. In ESFT, antigens proven to have specific $\mathrm{T}$ cell responses have been limited to EWS-FLI1 fusion gene products $(6,20,21)$. More recently, cancer-testis antigens (also termed cancergermline genes) were defined in 11 of 18 ESFT specimens and included MAGE-A3, A4, A6, A10, A12, C2 and GAGE-1, -2 and -8 (22). However, their expression levels were lower than those of other sarcomas, including osteosarcoma and rhabdomyosarcoma (22).

Among the tumor-associated antigens identified in malignant melanoma, some were later found in solid tumors in a significant association with poor prognosis (Table III). These include cancer-testis antigens MAGE-3 (23,24), MAGE-4 
Table III. Tumor-associated antigens showing prognostic significance in solid tumors.

\begin{tabular}{|c|c|c|c|c|}
\hline Antigen & Tumor & $\begin{array}{c}\text { No. of } \\
\text { samples } \\
(\% \text { positive })\end{array}$ & $\begin{array}{l}\text { Detection } \\
\text { procedure }\end{array}$ & Refs. \\
\hline \multicolumn{5}{|l|}{ Cancer testis } \\
\hline \multirow[t]{2}{*}{ MAGE-A3 } & NSCLC & $523(55.2)$ & RT-PCR & 23 \\
\hline & Pancreatic cancer & $57(44.0)$ & qRT-PCR & 24 \\
\hline \multirow[t]{5}{*}{ MAGE-A4 } & NSCLC $^{\mathrm{a}}$ & $19(36.8)$ & RT-PCR & 25 \\
\hline & Squamous cell & $153(56.9)$ & $\mathrm{IHC}$ & 26 \\
\hline & lung carcinoma & & & \\
\hline & Ovarian carcinoma & $53(57.0)$ & $\mathrm{IHC}$ & 27 \\
\hline & Bladder carcinoma & $908(4.0)^{\mathrm{b}}$ & IHC & 28 \\
\hline NY-ESO-1 & NSCLC & $523(26.6)$ & RT-PCR & 23 \\
\hline \multicolumn{5}{|c|}{ Overexpression } \\
\hline PRAME & Neuroblastoma & $95(33.7)^{b}$ & qRT-PCR & 29 \\
\hline \multirow[t]{2}{*}{ WT1 } & Soft tissue sarcomas & $52(32.7)^{\mathrm{b}}$ & qRT-PCR & 30 \\
\hline & Osteosarcoma & $37(27.0)^{\mathrm{b}}$ & IHC & 31 \\
\hline PBF & ESFT & $20(75.0)^{\mathrm{b}}$ & $\mathrm{IHC}$ & $\begin{array}{c}\text { Present } \\
\text { study }\end{array}$ \\
\hline $\begin{array}{l}\text { NSCLC, n } \\
\text { RT-PCR; Il } \\
\text { of samples }\end{array}$ & $\begin{array}{l}\text { all cell lung carcinon } \\
\text { mmunohistochemistry. } \\
\text { overexpression. }\end{array}$ & $\begin{array}{l}\text { ma; qRT-PCR, } \\
\text { aAdvanced stag }\end{array}$ & quantitative 1 & $\begin{array}{l}\text { real-time } \\
\text { ercentage }\end{array}$ \\
\hline
\end{tabular}

(25-28) and NY-ESO-1 (23), and an overexpression antigen, PRAME (29). Apart from melanoma-derived antigens, it has been reported that the overexpression of WT1 is associated with poor prognosis in bone and soft tissue sarcomas $(30,31)$ (Table III). Though WT1 was originally defined as the tumorsuppressor gene responsible for Wilms' tumor, antigenic peptides derived from it have recently been used as vaccines for hematopoietic malignancies and solid cancers (32). PBF is classified as an overexpression antigen as it is detected in some normal tissues by RT-PCR (9). In addition to ESFT, expression of PBF was found to be significantly associated with poor prognosis in patients with osteosarcoma, with statistical significance (Tsukahara et al, unpublished data).

The antigenic role of PBF in patients with ESFT remains to be defined by $\mathrm{T}$ cell responses specific to PBF-derived peptides. To this end, we recently developed a limiting dilution/ mixed lymphocyte peptide culture/tetramer/cytotoxicity assay by which the frequency and anti-tumor cytotoxicity of peripheral $\mathrm{T}$ lymphocytes directed against PBF were determined in patients with osteosarcoma (Tsukahara et al, unpublished data). This approach is also applicable to patients with ESFT. Another limitation of the present study is the small number of samples used, due mainly to the rare occurrence of ESFT in the Japanese population. It is, however, based on a consecutive series of patients treated at a single institute for more than 25 years.
In conclusion, the present analysis serves as a pilot study showing the prognostic significance of PBF for patients with ESFT. Large-scale analyses need to be conducted to verify the present findings if PBF-targeted immunotherapy for patients with ESFT is to be developed.

\section{Acknowledgments}

This work was supported by Grants-in-Aid from the Ministry of Education, Culture, Sports, Science and Technology of Japan (Grant No. 16209013 to N.S.), by Practical Application Research from the Japan Science and Technology Agency (Grant No. H14-2 to N.S.), by the Ministry of Health, Labour and Welfare (Grant No. H17-Gann-Rinsyo-006 to T.W), by the Postdoctoral Fellowship of the Japan Society for the Promotion of Science (Grant No. 02568 to T.T) and by the Northern Advancement Center for Science and Technology (Grant No. H18-Waka-075 to T.T). The authors thank Soichi Narutomi for his technical support.

\section{References}

1. Bernstein M, Kovar H, Paulussen M, Randall RL, Schuck A, Teot LA and Juergens H: Ewing's sarcoma family of tumors: current management. Oncologist 11: 503-519, 2006.

2. Miser JS, Krailo MD, Tarbell NJ, et al: Treatment of metastatic Ewing's sarcoma or primitive neuroectodermal tumor of bone: evaluation of combination ifosfamide and etoposide - a Children's Cancer Group and Pediatric Oncology Group study. J Clin Oncol 22: 2873-2876, 2004

3. Bernstein ML, Devidas M, Lafreniere D, et al: Intensive therapy with growth factor support for patients with Ewing tumor metastatic at diagnosis: Pediatric Oncology Group/Children's Cancer Group Phase II Study 9457 - a report from the Children's Oncology Group. J Clin Oncol 24: 152-159, 2006.

4. Marcove RC, Mike V, Huvos AG, Southam CM and Levin AG: Vaccine trials for osteogenic sarcoma. A preliminary report. CA Cancer J Clin 23: 74-80, 1973.

5. Neff JR and Enneking WF: Adoptive immunotherapy in primary osteosarcoma. An interim report. J Bone Joint Surg Am 57: 145-148, 1975.

6. Dagher R, Long LM, Read EJ, et al: Pilot trial of tumor-specific peptide vaccination and continuous infusion interleukin-2 in patients with recurrent Ewing sarcoma and alveolar rhabdomyosarcoma: an inter-institute NIH study. Med Pediatr Oncol 38: 158-164, 2002.

7. Maki RG: Future directions for immunotherapeutic intervention against sarcomas. Curr Opin Oncol 18: 363-368, 2006.

8. Kawaguchi S, Wada T, Tsukahara T, Ida K, Torigoe T, Sato N and Yamashita T: A quest for therapeutic antigens in bone and soft tissue sarcoma. J Transl Med 3: 31, 2005.

9. Tsukahara T, Nabeta Y, Kawaguchi S, et al: Identification of human autologous cytotoxic T-lymphocyte-defined osteosarcoma gene that encodes a transcriptional regulator, papillomavirus binding factor. Cancer Res 64: 5442-5448, 2004.

10. Boeckle S, Pfister H and Steger G: A new cellular factor recognizes E2 binding sites of papillomaviruses which mediate transcriptional repression by E2. Virology 293: 103-117, 2002.

11. Urano F, Umezawa A, Yabe H, Hong W, Yoshida K, Fujinaga K and Hata J: Molecular analysis of Ewing's sarcoma: another fusion gene, EWS-E1AF, available for diagnosis. Jpn J Cancer Res 89: 703-711, 1998.

12. Enneking WF: A system of staging musculoskeletal neoplasms. Clin Orthop Relat Res: 9-24, 1986.

13. Jaffe N, Paed D, Traggis D, Salian S and Cassady JR: Improved outlook for Ewing's sarcoma with combination chemotherapy (vincristine, actinomycin D and cyclophosphamide) and radiation therapy. Cancer 38: 1925-1930, 1976.

14. Nesbit Jr ME, Gehan EA, Burgert Jr EO, et al: Multimodal therapy for the management of primary, nonmetastatic Ewing's sarcoma of bone: a long-term follow-up of the First Intergroup study. J Clin Oncol 8: 1664-1674, 1990. 
15. Wilbur JR, Sutow WW, Sullivan MP and Gottlieb JA: Chemotherapy of sarcomas. Cancer 36: 765-769, 1975.

16. Rosen G: Current management of Ewing's sarcoma. Prog Clin Cancer 8: 267-282, 1982 .

17. Kaneko M, Nishihira H, Mugishima H, et al: Stratification of treatment of stage 4 neuroblastoma patients based on $\mathrm{N}$-myc amplification status. Study Group of Japan for Treatment of Advanced Neuroblastoma, Tokyo, Japan. Med Pediatr Oncol 31: $1-7,1998$

18. Ahmed A, Gilbert-Barness E and Lacson A: Expression of c-kit in Ewing family of tumors: a comparison of different immunohistochemical protocols. Pediatr Dev Pathol 7: 342-347, 2004.

19. Kawaguchi S, Wada T, Nagoya S, et al: Extraskeletal myxoid chondrosarcoma: a multi-institutional study of 42 cases in Japan. Cancer 97: 1285-1292, 2003.

20. Mackall CL, Berzofsky JA and Helman LJ: Targeting tumor specific translocation in sarcomas in pediatric patients for immunotherapy. Clin Orthop 373: 25-31, 2000.

21. Meyer-Wentrup F, Richter G and Burdach S: Identification of an immunogenic EWS-FLI1-derived HLA-DR-restricted T helper cell epitope. Pediatr Hematol Oncol 22: 297-308, 2005

22. Jacobs JF, Brasseur F, Hulsbergen-van de Kaa CA, et al: Cancer-germline gene expression in pediatric solid tumors using quantitative real-time PCR. Int J Cancer 120: 67-74, 2007.

23. Gure AO, Chua R, Williamson B, et al: Cancer-testis genes are coordinately expressed and are markers of poor outcome in nonsmall cell lung cancer. Clin Cancer Res 11: 8055-8062, 2005.

24. Kim J, Reber HA, Hines OJ, et al: The clinical significance of MAGEA3 expression in pancreatic cancer. Int J Cancer 118: 2269-2275, 2006
25. Yoshida N, Abe H, Ohkuri T, et al: Expression of the MAGE-A4 and NY-ESO-1 cancer-testis antigens and T cell infiltration in non-small cell lung carcinoma and their prognostic significance. Int J Oncol 28: 1089-1098, 2006.

26. Bolli M, Kocher T, Adamina M, et al: Tissue microarray evaluation of Melanoma antigen E (MAGE) tumor-associated antigen expression: potential indications for specific immunotherapy and prognostic relevance in squamous cell lung carcinoma. Ann Surg 236: 785-793, 2002

27. Yakirevich E, Sabo E, Lavie O, Mazareb S, Spagnoli GC and Resnick MB: Expression of the MAGE-A4 and NY-ESO-1 cancer-testis antigens in serous ovarian neoplasms. Clin Cancer Res 9: 6453-6460, 2003.

28. Kocher T, Zheng M, Bolli M, et al: Prognostic relevance of MAGE-A4 tumor antigen expression in transitional cell carcinoma of the urinary bladder: a tissue microarray study. Int J Cancer 100: 702-705, 2002.

29. Oberthuer A, Hero B, Spitz R, Berthold F and Fischer M: The tumor-associated antigen PRAME is universally expressed in high-stage neuroblastoma and associated with poor outcome. Clin Cancer Res 10: 4307-4313, 2004.

30. Sotobori T, Ueda T, Oji Y, et al: Prognostic significance of Wilms tumor gene (WT1) mRNA expression in soft tissue sarcoma. Cancer 106: 2233-2240, 2006.

31. Srivastava A, Fuchs B, Zhang K, et al: High WT1 expression is associated with very poor survival of patients with osteogenic sarcoma metastasis. Clin Cancer Res 12: 4237-4243, 2006.

32. Sugiyama H: Cancer immunotherapy targeting Wilms' tumor gene WT1 product. Expert Rev Vaccines 4: 503-512, 2005. 